\title{
Primary Hyperparathyroidism Patients with Positive Preoperative Sestamibi Scan and Negative Ultrasound Are More Likely to Have Posteriorly Located Upper Gland Adenomas (PLUGs)
}

\author{
Avital Harari, MD ${ }^{1}$, Elliot Mitmaker, $\mathrm{MD}^{2}$, Raymon H. Grogan, $\mathrm{MD}^{2}$, James Lee, $\mathrm{MD}^{3}$, Wen Shen, $\mathrm{MD}^{2}$, \\ Jessica Gosnell, $\mathrm{MD}^{2}$, Orlo Clark, $\mathrm{MD}^{2}$, and Quan-Yang Duh, $\mathrm{MD}^{2}$ \\ ${ }^{1}$ Department of Surgery, University of California, Los Angeles, CA; ${ }^{2}$ Division of Endocrine Surgery, University of \\ California, San Francisco, CA; ${ }^{3}$ Division of Endocrine Surgery, Columbia University Medical Center, New York, NY
}

\begin{abstract}
Background. Standard preoperative imaging for primary hyperparathyroidism usually includes sestamibi scanning (MIBI) and ultrasound (US). In a subset of patients with a positive MIBI and a negative US, we hypothesize that the parathyroid adenomas are more likely to be located posteriorly in the neck, where anatomically they are more difficult to detect by US.

Methods. We retrospectively reviewed the records of 661 patients treated for primary hyperparathyroidism between 2004 and 2009 at a tertiary referral center. We included patients who for their first operation had a MIBI that localized a single lesion in the neck and an US that found no parathyroid adenoma. We excluded patients with persistent or recurrent hyperparathyroidism, and patients with MIBIs that were negative, that had more than one positive focus, or that had foci outside of the neck. Sixty-six cases were included in the final analysis.

Results. A total of 54 patients $(83 \%)$ had a single adenoma, $4(6 \%)$ had double adenomas, and $7(11 \%)$ had hyperplasia. Thirty-three patients $(51 \%)$ had a single upper gland adenoma; 19 of these $(58 \%)$ were posteriorly located upper gland adenomas (PLUGs). PLUGs occurred more
\end{abstract}

Presented as a poster at the American Association of Endocrine Surgeons; Pittsburgh, Pennsylvania, April 18-20, 2010.

(C) The Author(s) 2011. This article is published with open access at Springerlink.com

First Received: 15 September 2010;

Published Online: 5 January 2011

A. Harari, MD

e-mail: aharari@mednet.ucla.edu often on the right side than on the left $(P=0.048$, Fisher's test). PLUGs were also larger than other single adenomas (mean 1.85 vs. $1.48 \mathrm{~cm}, P=0.021, t$-test). Seventy-six percent of patients successfully underwent a unilateral or focused exploration. Six patients $(9 \%)$ had persistent disease, which is double our group's overall average (4-5\%). Conclusions. Primary hyperparathyroid patients with preoperative positive MIBI and negative US are more likely to have PLUGs.

Primary hyperparathyroidism (PHPT) is a common cause of hypercalcemia, diagnosed in approximately 1 in 1000 people in the United States each year. ${ }^{1-3}$ The causes of PHPT include a single adenoma (80 to $85 \%$ ), double adenomas ( 2 to $12 \%$ ), hyperplasia (5 to $15 \%$ ), or parathyroid carcinomas $(<1 \%)$., ${ }^{2,-7}$

The only curative treatment for PHPT is parathyroidectomy. Most parathyroid surgeons in the US use preoperative localization studies to guide a more focused operation and offer a unilateral minimally invasive surgical technique. ${ }^{7}$ If positive, this can limit the dissection to the abnormal parathyroid gland and thus substantially decrease operation time. ${ }^{8,9}$ For preoperative localization before firsttime operations, most surgeons will order a ${ }^{99 \mathrm{~m}} \mathrm{Tc}$-sestamibi scan (MIBI) and an ultrasound (US) as their initial imaging studies. ${ }^{7}$

The sensitivity of MIBI for detection of solitary adenomas ranges from 68 to $95 \%$. US carries a wide range of sensitivities (33 to $89 \%$ ), depending on the experience of the sonographer, for the detection of solitary parathyroid adenomas. ${ }^{7,8,10-14}$ However, a preoperative approach that combines both the anatomic information of sonography and the physiologic information of scintigraphy has been 
shown to predict the presence and location of solitary adenomas more accurately than either technique alone. ${ }^{8}$ When combined, the overall sensitivity can be increased up to $95 \%$. $^{7}$

Despite this, a subset of patients will have a positive MIBI and a negative US preoperatively before their firsttime exploration for PHPT. In this case, because one of the studies is positive, most surgeons would go straight to surgery rather than order more imaging studies. Previous studies have not focused primarily on what a surgeon should expect to encounter intraoperatively with this specific combination of imaging results in the neck.

We hypothesized that in this subset of patients, the parathyroid adenomas are more likely to be located posteriorly in the neck, where anatomically they are more difficult to detect by US. Because, embryologically, descended upper parathyroid glands are located more posteriorly in the neck, we also hypothesized that most of these posterior lesions are descended upper parathyroid glands located in the tracheoesophageal groove or retroesophageally.

\section{METHODS}

We retrospectively reviewed the records of all patients treated for PHPT between 2004 and 2009 from a prospective parathyroid database of a tertiary referral center. We included patients who underwent their first parathyroid operation, had a MIBI that localized only a single lesion in the neck, and had an US that found no parathyroid adenoma. We excluded patients with persistent, recurrent, secondary, or tertiary hyperparathyroidism. We also excluded any patients with MIBIs that were negative, that had more than one positive focus, or that had foci outside of the neck. All USs were performed by the radiology department of our hospital. The MIBI imaging results were not routinely available to the sonographers. For patients who had no prior localization studies, we routinely perform MIBI and US on the same day, but not in any particular sequence.

One of the two hospitals did not measure intraoperative parathyroid hormone (ioPTH) levels during this study period. We have previously shown that when both MIBI and US are positive and concordant, a focused exploration of just one gland without ioPTH has a similar success rate to the use of ioPTH. We also showed that when only one localizing study is positive, we should exclude hyperplasia by exploring one additional gland (unilateral exploration). Thus, the guidelines that the surgeons used when ioPTH was not available were: (1) if two localizing studies were positive, a focused exploration of one gland was performed; (2) if only one localizing study was positive, a unilateral exploration of both glands was performed to confirm that the other ipsilateral parathyroid gland was normal and to rule out hyperplasia; and (3) if there was no positive localizing study, a four-gland bilateral exploration was performed. We tend to use ioPTH aspirates of the excised glands to confirm parathyroid tissue. When ioPTH was not available, analysis of frozen sections was used to confirm pathology.

Single adenomas were defined as a single parathyroid adenoma found at the time of first operation. Upper or lower glands were designated by the surgeon at the time of operation, depending on their relative position to the recurrent laryngeal nerve. Glands posterior to the nerve were designated as upper glands. Those anterior to the nerve were designated as lower glands. Posteriorly located upper gland adenomas (PLUGs) were defined as those glands that were descended upper parathyroid glands located in the tracheoesophageal groove or in a retroesophageal location.

A double adenoma was defined as two confirmed hypercellular parathyroid glands, either found at the time of first operation or found at reoperation. If two diseased glands were excised and one was a PLUG, they were counted as double adenoma. Multigland disease was defined as three or four parathyroid adenomas found at the time of first operation or at reoperation.

Persistent hyperparathyroidism was defined as hypercalcemia encountered within six months of the first operation. The one exception was a patient with normocalcemic PHPT, in whom persistence was defined as persistently increased parathyroid hormone levels postoperatively. Most patients are followed by their referring endocrinologists after the postoperative clinic visit. Patients are instructed to have calcium level checked by the endocrinologists six months after surgery, then yearly, and to return to us if the levels are abnormal.

\section{RESULTS}

Of 661 patients, 66 met the inclusion criteria and were included in the final analysis. Table 1 shows the demographics of this population.

Fifty-four patients (83\%) had a single adenoma, $4(6 \%)$ had double adenomas, and 7 (11\%) had hyperplasia. No patients had parathyroid cancer. One patient who underwent bilateral neck exploration was excluded from the analysis of the number of glands causing PHPT because of excision of one lower gland with only mild hypercellularity, with no drop in ioPTH, and hence a known failure intraoperatively. The patient refused reoperation, and thus we cannot definitively conclude how many glands were causing his disease.

A total of $33(61 \%)$ of 54 patients with single adenomas had a single upper gland adenoma; 19 (58\%) of the 33 upper glands were PLUGs that had descended into the 
TABLE 1 Patient demographics

\begin{tabular}{|c|c|}
\hline Characteristic & Value \\
\hline Average age (year) & 59 \\
\hline Female sex & $62 \%$ \\
\hline Average body mass index & 27.47 \\
\hline $\begin{array}{l}\text { Average calcium level } \\
\text { (preoperative) }\end{array}$ & $10.79 \mathrm{mg} / \mathrm{dl}(n=62)$ \\
\hline $\begin{array}{l}\text { Average calcium level (within } 6 \\
\text { months after } \\
\text { parathyroidectomy) }\end{array}$ & $9.01 \mathrm{mg} / \mathrm{dl}(n=65)$ \\
\hline $\begin{array}{l}\text { Average calcium level ( }>6 \text { months } \\
\text { after parathyroidectomy) }\end{array}$ & $9.46 \mathrm{mg} / \mathrm{dl}(n=21)$ \\
\hline Average PTH level (preoperative) & $139.4 \mathrm{pg} / \mathrm{ml}(n=61)$ \\
\hline $\begin{array}{l}\text { Average PTH level (within } 6 \text { months } \\
\text { after parathyroidectomy) }\end{array}$ & $34.55 \mathrm{pg} / \mathrm{ml}(n=64)$ \\
\hline $\begin{array}{l}\text { Average PTH level ( }>6 \text { months } \\
\text { after parathyroidectomy) }\end{array}$ & $46.7 \mathrm{pg} / \mathrm{ml}(n=15)$ \\
\hline $\begin{array}{l}\text { Average operating room time } \\
\text { (patients with no concomitant } \\
\text { thyroid operations) }\end{array}$ & $92 \mathrm{~min}$ \\
\hline
\end{tabular}

PTH parathyroid hormone

tracheoesophageal groove $(n=16)$ or into the retroesophageal space $(n=3)$ (Fig. 1). PLUGs occurred more often on the right side than on the left $(P=0.048$, Fisher's test). PLUGs were also statistically larger than other single adenomas (mean 1.85 vs. $1.48 \mathrm{~cm}, P=0.021, t$-test). There was no statistical difference in body mass index (BMI; $P=0.3$ ) between those that had PLUG adenomas (BMI 26.3) and those that had other types of single adenomas (BMI 28.9).

In those patients who had lower single glands adenomas found, $55 \%$ (11 of 20) had disease that was atypical in appearance or that was found in locations other than the normal position. The atypical areas included anterolateral/ beneath the thyroid capsule $(n=1)$; thymus/thyrothymic

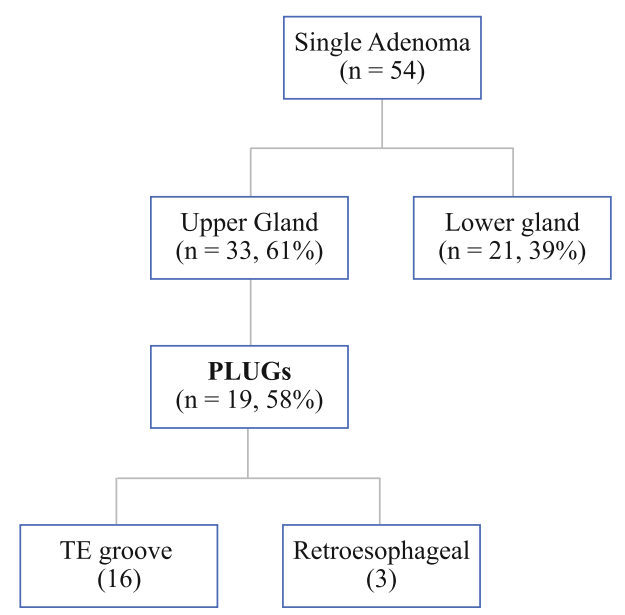

FIG. 1 Distribution of single adenoma glands ligament $(n=5)$; and posteromedial and associated with thyroid nodule $(n=1)$. The atypical appearances of the lower glands included bilobed appearance $(n=2)$; associated with multinodular goiter but in a normal location $(n=1)$; and wormlike appearance $(n=1)$.

Seventy-six percent of patients successfully underwent a unilateral or focused exploration. At last follow-up, the postoperative normocalcemia rate when ioPTH testing was used with a $>50 \%$ drop was $92 \%$ (34 of 37). The normocalcemia rate with no use of ioPTH was $93 \%$ (26 of 28). Thus, use of ioPTH showed no difference in the rate of normocalcemia.

When looking at the appearance on MIBI, if it showed a single bright focus that was in the medial position, $46.6 \%$ were found intraoperatively to be PLUGs (7 of 15). Of the 19 PLUGs, 17 of them $(89 \%)$ had midlevel $(n=6)$ or inferior $(n=11)$ MIBI predictions. All patients in which PLUGs were found had a preoperative MIBI that showed a single focus in the medial position.

Six patients $(9 \%)$ had persistent disease, which is double our institution's overall average (4 to 5\%). These included four patients with bilateral operations (all performed with ioPTH) and two patients with unilateral operations (in which no ioPTH was used). Table 2 provides details on these operations.

All patients had a positive adenoma found intraoperatively on the side of the preoperative MIBI result $(100 \%$ sensitive for disease on the side that the MIBI indicated). However, in 11 patients, multiple gland disease (including two or more abnormal glands) was found either at the time of initial operation or at a subsequent operation. Table 3 outlines the preoperative MIBI results in these particular patients and indicates where the glands were ultimately found.

\section{DISCUSSION}

In this study, we found that patients with a single positive MIBI focus in the neck and a negative US have a similar distribution of gland pathology as the entire population of PHPT patients. However, patients with this particular combination of imaging studies have an unusually high incidence of posteriorly located upper glands (PLUGs).

Embryologically, upper gland adenomas are derived from the fourth branchial pouch. ${ }^{15}$ These upper glands tend to be more consistent in location than the lower glands with most $(>90 \%)$ upper glands located deep in relation to the mid portion of the superior pole of the thyroid near the cricothyroid junction. ${ }^{8}$ Infrequently, the superior glands can be seen more inferiorly, deep in relation to the midpole of the thyroid lobes $(4 \%)$, or they may be located at or 
TABLE 2 Persistent disease

\begin{tabular}{|c|c|c|c|c|c|}
\hline $\begin{array}{l}\text { Type of } \\
\text { operation }\end{array}$ & $\begin{array}{l}\text { MIBI } \\
\text { prediction }\end{array}$ & $\begin{array}{l}\text { ioPTH } \\
\text { used? }\end{array}$ & Percentage ioPTH drop & Intraoperative findings & Postoperative course/follow-up \\
\hline Bilateral & Right inferior & Yes & Zero & $\begin{array}{l}\text { RL gland excised and right thyroid } \\
\text { lobe taken; RU and LL never } \\
\text { found }\end{array}$ & Patient refused reoperation \\
\hline Bilateral & $\begin{array}{l}\text { Posteromedial } \\
\text { right upper }\end{array}$ & Yes & $\begin{array}{l}86 \% \text { (slow drop; this delay was } \\
\text { the reason for bilateral neck } \\
\text { exploration) }\end{array}$ & $\begin{array}{l}\text { PLUG found in area of MIBI } \\
\text { prediction on right TE groove; } \\
\text { right thyroid lobe taken as well } \\
\text { (follicular neoplasm); RL never } \\
\text { found; normal LU and LL } \\
\text { observed }\end{array}$ & Lost to follow-up \\
\hline Bilateral & Left inferior & Yes & $52 \%$ & $\begin{array}{l}\text { RL and LL taken; RU and LU } \\
\text { seemed normal }\end{array}$ & $\begin{array}{l}\text { An additional gland was removed } \\
\text { at a reoperation, so likely this } \\
\text { was hyperplasia }\end{array}$ \\
\hline Bilateral & Left superior & Yes & $67 \%$ & $\begin{array}{l}\text { Subtotal parathyroidectomy; left } \\
\text { part of LL in situ }\end{array}$ & $\begin{array}{l}\text { This patient had persistently } \\
\text { increased PTH with } \\
\text { normocalcemic } \\
\text { hyperparathyroidism; no } \\
\text { reoperation offered; } \\
\text { investigating other causes of } \\
\text { possible secondary } \\
\text { hyperparathyroidism }\end{array}$ \\
\hline Unilateral & $\begin{array}{l}\text { Posterior left } \\
\text { upper }\end{array}$ & No & NA & LU and LL removed & $\begin{array}{l}\text { Lost to follow-up, did not return } \\
\text { for reoperation; likely had } \\
\text { hyperplasia, given persistence } \\
\text { after unilateral exploration only }\end{array}$ \\
\hline Unilateral & Right inferior & No & NA & $\begin{array}{l}\text { RU PLUG taken as focused } \\
\text { exploration }\end{array}$ & $\begin{array}{l}\text { Lost to follow-up; likely had }>1 \\
\text { gland diseased }\end{array}$ \\
\hline
\end{tabular}

MIBI sestamibi scan, $P T H$ parathyroid hormone, ioPTH intraoperative PTH, $R L$ right lower, $R U$ right upper, $L L$ left lower, $L U$ left upper, $T E$ tracheoesophageal, $P L U G$ posteriorly located upper gland adenoma, $N A$ not applicable

TABLE 3 MIBI predictions associated with multiple-gland disease ${ }^{\text {a }}$

\begin{tabular}{ll}
\hline MIBI prediction & Type of disease \\
\hline $\begin{array}{l}\text { Right middle } \\
\text { Right superior } \\
\text { Left inferior }\end{array}$ & $\begin{array}{l}\text { Double: RU and RL PT adenomas } \\
\text { Pouble: LU and LL (intrathyroidal) PT } \\
\text { adenomas }\end{array}$ \\
$\begin{array}{l}\text { Posterior to left } \\
\text { upper }\end{array}$ & PT hyperplasia (4-gland disease) \\
Right middle & Double: RU and RL PT adenomas \\
Right inferior & PT hyperplasia; RU was a PLUG \\
Right superior & PT hyperplasia (4-gland disease) \\
Right posterior & PT 3-gland hyperplasia: LU, LL, RU PT \\
inferior & involved \\
Left inferior (1/09) & Double: RL and LL PT adenomas \\
Left middle & Double: Right PLUG, LL PT adenomas \\
Left superior & PT hyperplasia (4-gland disease)
\end{tabular}

MIBI sestamibi scan, $R U$ right upper, $R L$ right lower, $L U$ left upper, $L L$ left lower, $P T$ parathyroid, $P L U G$ posteriorly located upper gland adenoma

a All MIBI predictions are provided in relation to the thyroid lobe on the ipsilateral side above the most superior aspect of the thyroid (3\%). Rarely, the superior glands can be found in the retropharyngeal $(1 \%)$ or retroesophageal $(1 \%)(2 \%$ PLUG) spaces, or in the thyroid gland itself $(0.2 \%){ }^{8}$

In this investigation, we have shown that among the single upper glands found, there is a far higher than normal (58 vs. $2 \%$, as noted above) proportion of these PLUGs when preoperative imaging shows a single positive MIBI focus in the neck and a negative US. Perrier et al. introduced a novel nomenclature to describe parathyroid adenoma location in the neck. If one uses their nomenclature, PLUGs would likely be labeled as B or C glands (those found in the tracheoesophageal groove). ${ }^{16}$

Kim et al.'s study showed that in patients with a single focus at MIBI, only $4.5 \%$ of abnormal glands were found in a different quadrant on the same side. ${ }^{17}$ Interestingly, most of the PLUGs in our series were predicted by MIBI to be in middle or inferior locations (Fig. 2). If one looked at this fact alone, it may suggest to some surgeons that they ought to search for an anterior lower gland, when in fact it is a descended posterior upper gland that they may find. Understanding the combination of these positive MIBIs 
FIG. 2 Sestamibi scan of a right-sided, posteriorly located upper gland adenoma

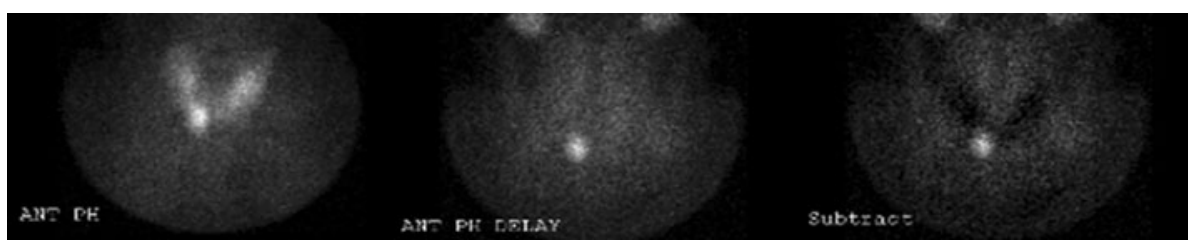

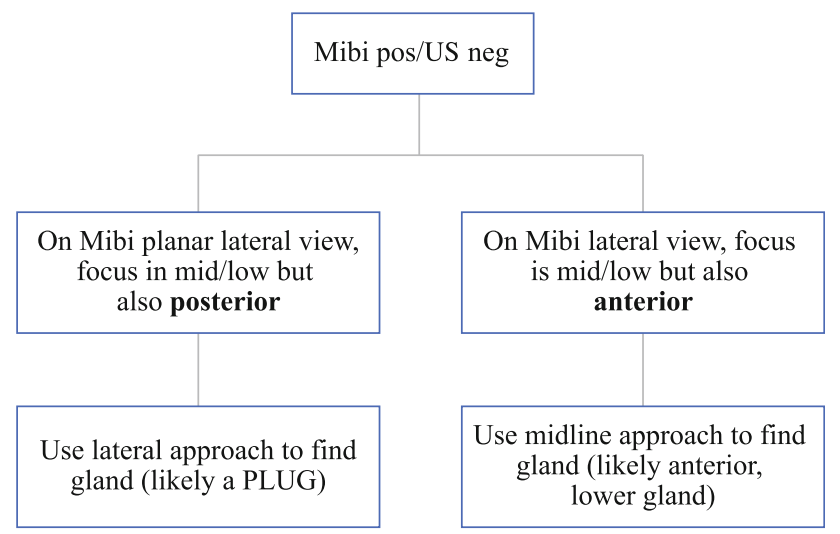

FIG. 3 Algorithm to determine the most efficient approach to find the gland

with the knowledge of a negative US can guide surgeons to look for a PLUG earlier than they would otherwise, thus decreasing operating room time.

Figure 3 is a simple algorithm that our group has come up with for surgeons that encounter this specific scenario of a negative US and a single MIBI focus in the neck. The figure systematically outlines our group's approach regarding the areas that one should look at intraoperatively to find the parathyroid adenomas. This method may not be routinely used by other surgeons. It is important to realize that one can excise both upper and lower adenomas by either an anterior approach (via a midline incision) or a lateral approach (via an incision just lateral to the midline). Conversion from a unilateral to a bilateral exploration should be anticipated at initial incision. In those in whom we anticipate a high risk for bilateral exploration, we will typically start with a small midline incision and use an anterior approach. However, even if a surgeon begins with a lateral incision/lateral approach, he or she can still convert to a bilateral exploration by extending the incision medially.

It is curious why 22 lower gland adenomas were not seen on US. The superficial location of these glands allows modern US equipment to give detailed images regarding their structure. ${ }^{18}$ We believe that part of the reason that $55 \%$ of lower glands in our study were not visualized was that they were located in an aberrant location or appeared slightly abnormal. It is unclear why the other $45 \%$ were not seen on US, however. Figure 4 demonstrates the locations of all single-gland adenomas.

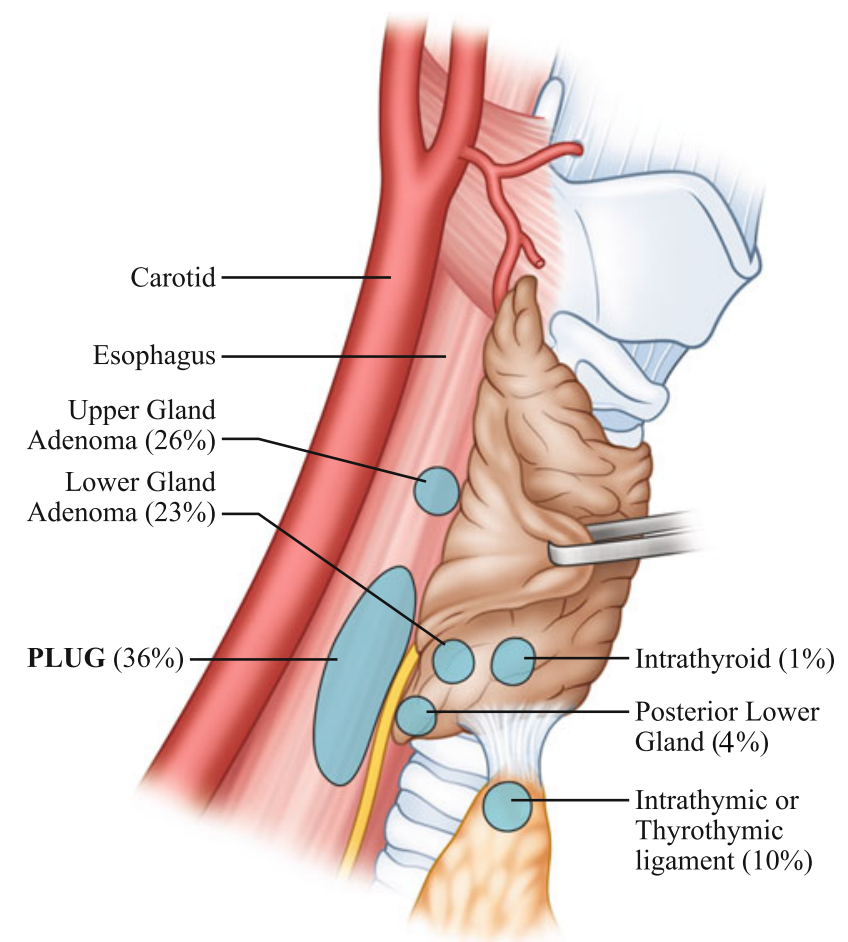

FIG. 4 Distribution of single-gland adenomas $(n=54)$

We should note that we excluded all patients with MIBI that revealed ectopic foci outside of the neck. Some of these patients will have MIBI that reveal mediastinal or undescended parathyroid adenomas. These patients will also have negative US. Our team looked closely at those patients with a single positive focus on MIBI in the neck only. Thus, it is important for the parathyroid surgeon to look closely at MIBI images themselves and recognize ectopic foci to understand how best to approach these tumors.

Berber et al.'s study evaluated 1000 patients in a prospective study to determine factors affecting negative localization with both MIBI and US. ${ }^{19}$ Their results concluded that as BMI increases, the sensitivity of US and of MIBI will decrease. Their explanation was that the increased amount of subcutaneous tissues would affect the ability of the sonographic waves to detect abnormal glands in the neck as well as cause difficulty in performing the examination. We also anticipated that BMI might adversely affect the ability of an US to see a PLUG, which 
is typically located deep in the neck. However, we found no statistical difference in BMI between those that had PLUGs versus those that were found to have other types of single adenomas. We have interpreted this to mean that even though an obese patient is more likely to have nonlocalizing US than a nonobese patient (per Siperstein), if an obese patient has a positive MIBI and negative US, he or she has the same chance of having a PLUG as a nonobese patient with the same findings.

In conclusion, primary hyperparathyroid patients with preoperative positive MIBI and negative US are more likely to have PLUGs. In this scenario, when an US is negative and a MIBI scan predicts disease in a lower quadrant, surgeons should not assume that a lower gland adenoma is the cause. One must look at the lateral planar views to determine the best approach because most of these will be upper parathyroid tumors that have descended unto the tracheoesophageal groove.

\section{CONFLICT OF INTEREST None.}

OPEN ACCESS This article is distributed under the terms of the Creative Commons Attribution Noncommercial License which permits any noncommercial use, distribution, and reproduction in any medium, provided the original author(s) and source are credited.

\section{REFERENCES}

1. Shabtai M, Ben-Haim M, Muntz Y, et al. 140 consecutive cases of minimally invasive, radio-guided parathyroidectomy: lessons learned and long term results. Surg Endosc. 2003;17:688-91.

2. Carroll MF, Schade DS. A practical approach to hypercalcemia. Am Fam Physician. 2003;67:1959-66.

3. Pasieka J. Asymptomatic primary hyperparathyroidism. In: Duh QY, Clark OH, Kebebew E, eds. Textbook of Endocrine Surgery. 2nd ed. Philadelphia: Elsevier Saunders, 2005:419-93.

4. Palestro CJ, Tomas MB, Tronco GG. Radionuclide imaging of the parathyroid glands. Semin Nucl Med. 2005;35:266-76.
5. Taniegra ED. Hyperparathyroidism. Am Fam Physician. 2004;69: 333-9.

6. Milas M, Wagner K, Easley KA, et al. Double adenomas revisited: nonuniform distribution favors enlarged superior parathyroids (fourth pouch disease). Surgery. 2003;134:995-1003.

7. Patel CN, Salahudeen HM, Lansdown M, et al. Clinical utility of ultrasound and ${ }^{99 \mathrm{~m}} \mathrm{Tc}$ sestamibi SPECT/CT for preoperative localization of parathyroid adenoma in patients with primary hyperparathyroidism. Clin Radiol. 2010;65:278-87.

8. Johnson NA, Tublin ME, Ogilvie JB. Parathyroid imaging: technique and role in the preoperative evaluation of primary hyperparathyroidism. Am J Roentgenol. 2007;188:1706-15.

9. Harari A, Allendorf J, Shifrin A, et al. Negative preoperative localization leads to greater resource use in the era of minimally invasive parathyroidectomy. Am J Surg. 2009;197:769-73.

10. Ahuka AT, Wong KT, Ching AS, et al. Imaging for primary hyperparathyroidism-what beginners should know. Clin Radiol. 2004;59:967-76.

11. Sukan A, Reyhan M, Aydin M, et al. Preoperative evaluation of hyperparathyroidism: the role of dual-phase parathyroid scintigraphy and ultrasound imaging. Ann Nucl Med. 2008;22:123-31.

12. Haciyanli M, Genc H, Damburaci N, et al. Minimally invasive focused parathyroidectomy without using intraoperative parathyroid hormone monitoring or gamma probe. J Postgrad Med. 2009;55:242-6.

13. Tresoldi S, Pompili G, Maiolino R, et al. Primary hyperparathyroidism: can ultrasonography be the only preoperative diagnostic procedure? Radiol Med. 2009;114:1159-72.

14. Purcell GP, Dirbas FM, Jeffrey RB, et al. Parathyroid localization with high-resolution ultrasound and technetium Tc 99m sestamibi. Arch Surg. 1999;134:824-30.

15. Mariani G, Gulec SA, Rubello D, et al. Preoperative localization and radioguided parathyroid surgery. J Nucl Med. 2003;44: 1443-58.

16. Perrier ND, Edeiken B, Nunez R, et al. A novel nomenclature to classify parathyroid adenomas. World J Surg. 2009;33:412-6.

17. Kim CK, Kim S, Krynyckyi BR, et al. The efficacy of sestamibi parathyroid scintigraphy for directing surgical approaches based on modified interpretation criteria. Clin Nucl Med. 2002;27: 246-8.

18. Barraclough BM, Barraclough BH. Ultrasound of the thyroid and parathyroid glands. World J Surg. 2000;24:158-65.

19. Berber E, Parikh RT, Ballem N, et al. Factors contributing to negative parathyroid localization: an analysis of 1000 patients. Surgery. 2008;144:74-9. 